\title{
CLINICAL AND HISTOLOGICAL MANIFESTATIONS OF ALLERGY TO METHYL METHACRYLATE
}

\author{
Dalenda Hadyaoui \\ Department of Fixed Prosthodontics, Faculty of Dentistry, University of Monstir, Tunisia
}

\section{ARTICLE INFORMATION:}

\section{Article History:}

Received 12 February 2016

Accepted in revised form: 03 May 2016

Published:12 December 2016

\section{Corresponding author:}

Dalenda Hadyaoui

e-mail: dalendaresearch@gmail.com

Keywords:

Methacrylate, Prosthodontics, Allergy

\begin{abstract}
ABSTRCAT:
This article reports a case of a 52 year-old woman who experienced symptoms of allergic reactions which appeared few days after the placement of provisional fixed restorations. The indicated patch testing identified the methyl methacrylate as an allergen in this case. Therefore, the provisional restorations were removed and replaced by aluminum shells and polycarbonate prostheses. After healing, our patient underwent a crown lengthening for retention requirements; the saved fragment utilized for histological analysis. An inflammatory infiltrates and epithelial ulceration was found.
\end{abstract}

معلومات المقال

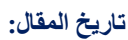
أستلم في :12 فبر اير 2016 : 2016 قبل في : 03 مايو 2016 فيراير 2016 نشر في : 12ديسمبر 2016

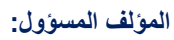

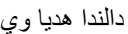
dalendaresearch@gmail.com:البريد الإلكتروني

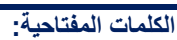
ميثًا اكريلات، التعويضات السنية، الحساسية

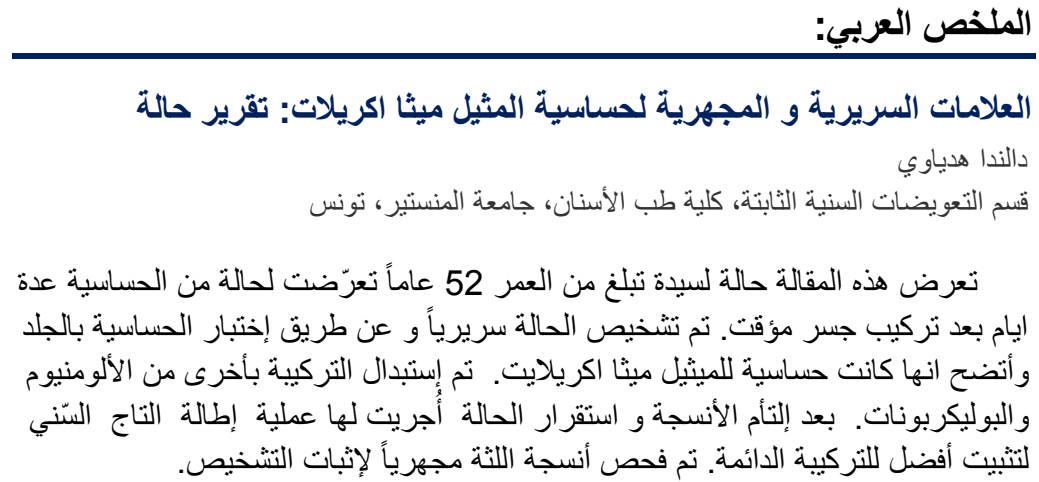




\section{INTRODUCTION}

An allergy is a hypersensitive reaction of the body in contact with a foreign substance (allergen) that does not cause disorder in most subjects. Whatever, is the irritant, allergic reactions fall into two main categories: immediate and delayed. ${ }^{1}$ In fact, the most frequent allergens used by practitioners are metals, rubber products, acrylates and resins ${ }^{2}$ that may be cytotoxic to both dentists and patients.

Acrylic resin is widely used in dentistry in many forms, ${ }^{3}$ such as composite for filling teeth, as bonding agents, and in the manufacture of artificial crowns. ${ }^{2}$ The latter is repeatedly used as interim fixed restorations, but adverse events seem infrequent. The substances included are methyl methacrylate (MMA), triethylene glycol dimethacrylate (TGDMA) and poly-methyl methacrylate. ${ }^{2}$

Acrylic resins polymerize by conversion of monomers to polymers. According to their mechanism of the reaction, they are classified as chemical (auto), heat, light or microwave curing. ${ }^{4}$ Hollefeeld et $\mathrm{al}^{5}$ in 1981 , has determined for the first time residual MMA in maple syrup by headspace GC. Further studies reported that after polymerization, various amount of methyl methacrylate monomer remain in the acrylic resin. ${ }^{1,} 6$ Regarding the use of biopolymers in approximation to oral tissues, the monomer to polymer conversion and residual monomer content are too important factors involved in tissue reaction. ${ }^{4}$

Several methods were described in the literature to determine the amount of free monomer due to the polymerization reaction. Tashkov and Getchev ${ }^{5}$ reported the presence of unpolymerized methyl methacrylate in contact lenses and glasses. A gas chromatography method has been described to study the influence of both the optical properties of the product and its tolerance by the organism including its tendency to cause allergies.

Collateral studies in dental medicine detected MMA released into the whole saliva and mainly in the salivary film on the fitting surface, this could be detected for up to one week after placing an auto polymerized appliance. ${ }^{7}$ Further research proved that most of the MMA released occurred 24 hours after insertion of the Orthoresin appliance in the oral cavity (Stafford and Brooks (1985), and Lamb (1982). ${ }^{7}$
Authors demonstrated that biodegradation of acrylic based resin leads to the production of leachable potentially toxic agents. ${ }^{3}$ The most frequent are residual monomer, which in turn may induce a series of biological responses on cells and tissues. This agrees with the findings of Sadamori et al, who suggested that residual monomer contents decreased with the increase of time span. Whereas, the most of the monomer loss was recorded within five years. ${ }^{7}$

Additionally, residual monomer was tested according to the polymerization technique, where heatpolymerized methyl methacrylate showed significantly fewer remaining monomer. ${ }^{4}$ On the other hand, and according to the polishing technique, the findings of Braun $^{9}$ recorded the highest level of residual monomer for both kind auto and thermo-polymerized resins with both mechanical and chemical polishing. Whereas, Nunes De Mello et al ${ }^{10}$ reported the highest values of residual monomer with chemical polishing meanwhile mechanical polishing led to the lowest.

In fact, residual monomer formed by incomplete polymerization has been determined as an allergen in contact stomatitis induced by the acrylic resin. Such allergic reactions were also found by Fisher ${ }^{11}$ for methyl methacrylate monomer in contact with skin and oral mucosa which probably explained the absence of hypersensitivity when polymerization of methyl methacrylate resin is complete.

Several investigative methods, for this type of allergies, have been suggested by researches such as patch testing which is useful or patients with marked oral and facial symptoms related to dental materials, and also, beneficial in facial dermatitis or respiratory symptoms which are likely related to dental personnel practice. Whatever the allergic reactions are, testing seems to be necessary, and the method of choice is patch testing. ${ }^{2}$ Nevertheless, when it comes to histologic investigations, there is a paucity of research. This is probably related to ethical rules.

This article describes a patient who showed a hypersensitive reaction to interim fixed restorations chairside fabricated using polymethyl- methacrylate resin, confirmed by a dermatologic patch test. In this case, gingivectomy wad indicated for prosthetic requirements. The saved gingival band is capitalized for a histological investigation. 


\section{CASE REPORT}

A healthy 52-year-old woman presented to the clinic of dental medicine, prosthodontic department, for the replacement of the missed first left maxillary molar. The medical history and extra-oral examination were irrelevant. The intraoral examination showed a good hygiene with the absence of any periodontal or mucosal disease, and a short molar. Radiographic examination revealed a favorable crown to root ratio.

The treatment plan included a gingivectomy for retention requirements followed by a ceramometallic bridge to replace the missing tooth. For that, abutments were prepared. Then, a provisional chairside restoration was manufactured using auto polymerized resin (TAB2000, Kerr, Ref 61770 ) with the strict respect of monomer/polymer ratio which is recommended by the manufacturer. A polyvinyl siloxane matrix was performed on the waxed diagnostic cast and used to absorb the peak of temperature during polymerization. It was cemented by provisional cement (temp band, Kerr, Ref 61086). This temporary restoration used to quantify the band of the gingival collar which will be incised.

After few days, the patient presented in emergency with a burning sensation of the tongue opposite the provisional restoration. The extraoral examination showed $s$ swollen right cheek. Furthermore, the intraoral examination revealed ulcerated oedematous gingiva with a white coating around the second left maxillary molar and on the inner surface of the cheek, and reddish areolas. The tongue examination revealed a depression corresponding to the impression of the provisional with some redness and non papillated areas. The most probable diagnosis was the hypersensitivity to auto polymerized resin or the eugenol content in the interim sealant.

Medicines composed by antibiotics, antifungal and antalgic were prescripted, and the temporary acrylic bridge was replaced by a preformed polycarbonate and aluminum shell crowns relined by a small amount of auto polymerized resin, then were mechanically polishing until the healing of the mucosa.
The patient was referred to a dermatologist for consultation, and to prove the diagnosis of hypersensitivity; patch test was done using the routine method described by Maxey. The test was carried out by cleaning the ventral surface of the forearm and placing spots approximately $10 \mathrm{~mm}$ square of several test materials on it: (a) liquid monomer; (b) auto polymerized resin made immediately before application; and (c) eugenol. The patches were placed in position with small gauze pads and hypoallergenic adhesive tape. The patients were instructed not to bathe the area and to leave the patch on for 48 hours( Fig. 1).

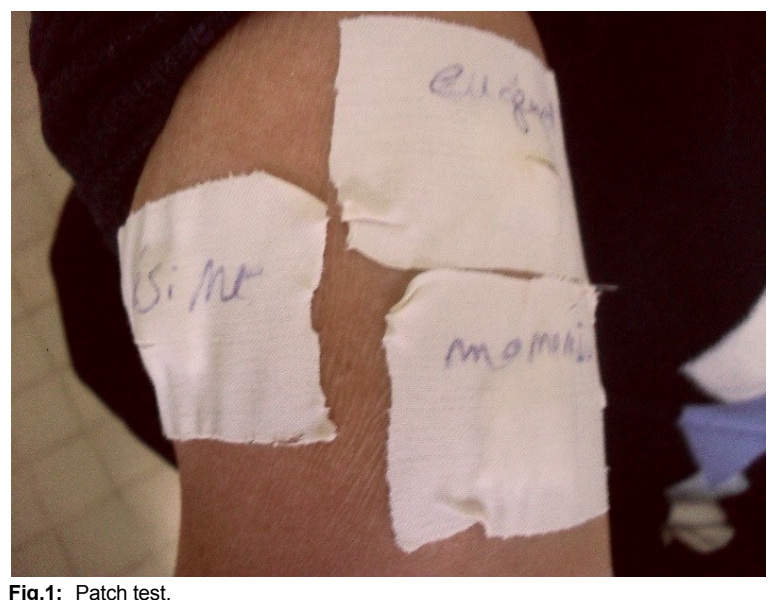

The following results were recorded at 48 hours. The intensity of the reaction is scored and recorded according to the rules of the International Contact Dermatitis Research Group (ICDRG). So, With the liquid monomer: the patient developed an intense allergic reaction that included vesicles, eruptions, and wide zones of erythema (Fig. 2).

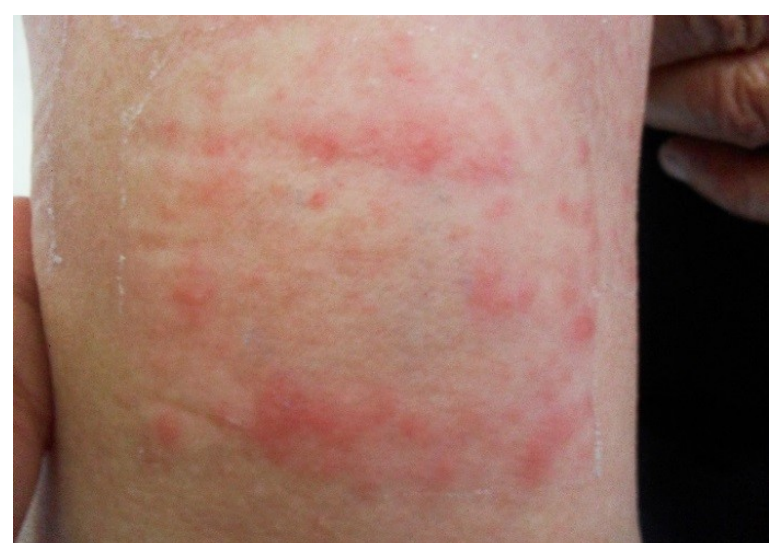

Fig.2: View of the high dermatological reaction to the monomer. 
With polymerized resin: the patient developed a weak reaction which showed moderate erythema with scarce papules which are considered a less severe reaction compared to the only monomer (Fig. 3).

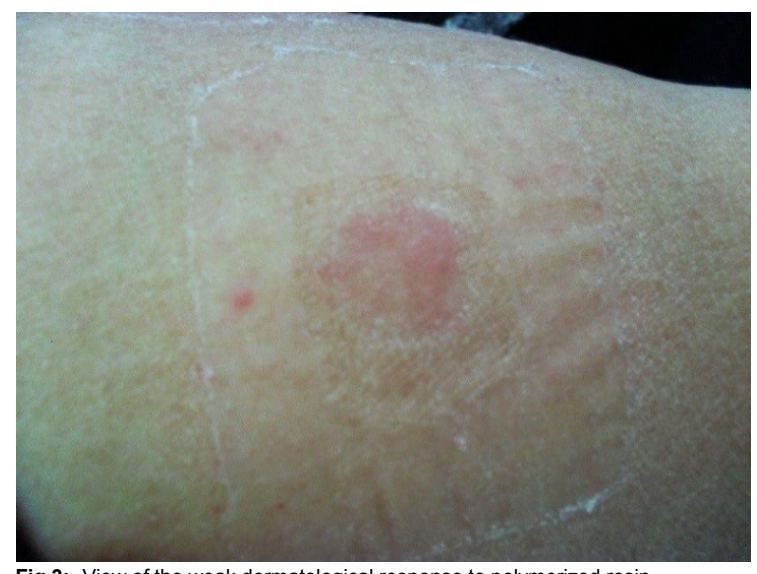

Fig.3: View of the weak dermatological response to polymerized resin.

With eugenol: the patient showed no allergic reactions and the response was negative (Fig. 4).

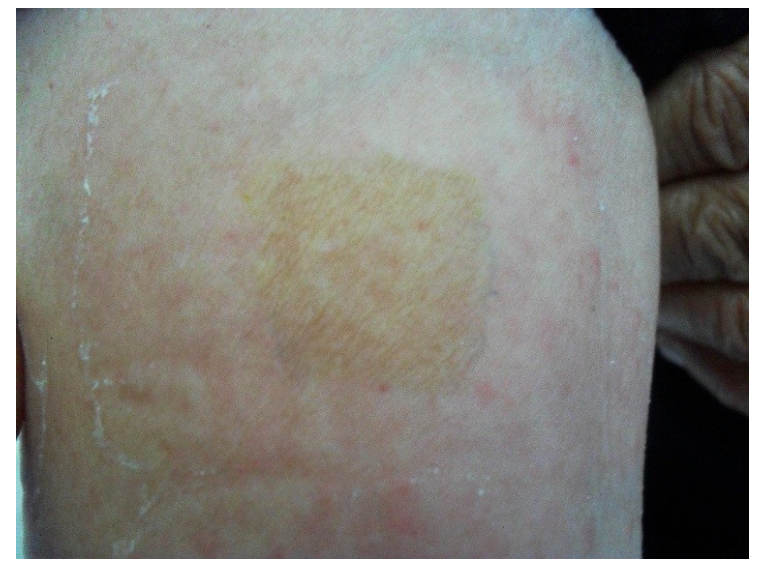

Fig.4: Negative dermatological reaction to eugenol.

So, the patch test confirmed the delayed allergy to the monomer MMA which was more severe than polymerized polymethylmethacrylate.

The patient was followed by a dermatologist until the healing of the gingiva and mucosa. Then, the gingivectomy was performed to improve retention as planned. The band of the gingival collar, which was considered as a gingival biopsy, was then fixed in formal and transferred to the department of anatomy and pathology.
The histological examination of the sample showed a tissue granulation. It was upholstered by a squamous epithelium slightly hyperplastic. It contained within the lamina propria polymorphic inflammatory infiltrates associating lymphocytes, plasmocytes, neutrophilic polynuclears and eosinophils of moderate abundance. The histological investigation showed base and margins of the gingival ulcer.( Figs. 5, 6).

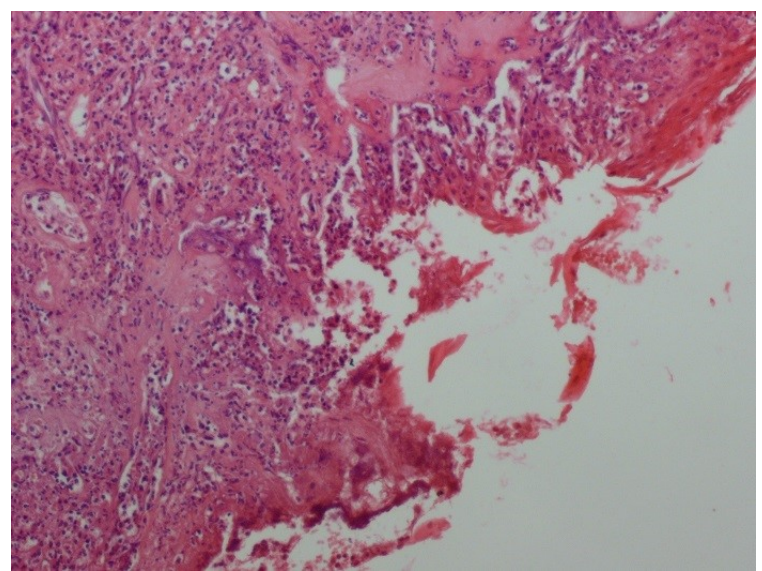

Fig.5: Wide epithelial ulceration covering a tissue granulation (HE x 100).

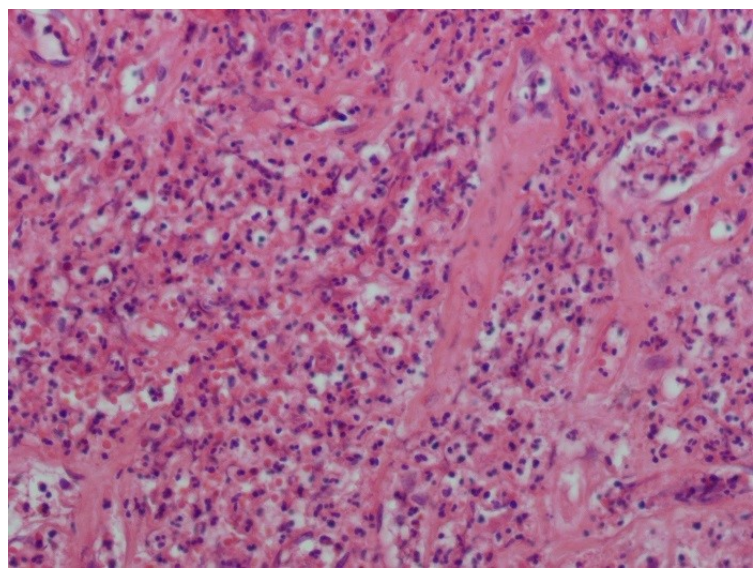

Fig.6: Polymorph inflammatory infiltrate associating lymphocytes, plasmocytes, and neutrophilic and eosinophilic polynuclears (HE x 200).

\section{DISCUSSION}

Allergic reactions to methyl polymethacrylate, however scarcely observed, have been described in the literature by several authors. Our clinical findings corroborate what has been reported by Hochman and Zalkind $^{1}$ where the patient complained of the same symptoms 48 hours after placing the provisional restoration, pain, swelling and burning sensations with severe stomatitis. The patch testing reported a serious 
positive reaction to the monomer including maculopapular rash, vesicle formations, as well as, a large zone of erythema compared to polymerized resins where the reaction was less severe than with monomer. As our patient experienced the same symptoms and reactions to the patch test, it is evident that monomer is more likely to induce allergy than polymerized resin itself. Likewise, positive responses were observed in allergic patients who had undergone orthodontic treatment, and placement of dentures.

Though, allergic reactions were likely to be delayed as described by Gonçalves et al, ${ }^{12}$ who reported hypersensitivity localized symptoms 30 days after the placement of self-curing methyl methacrylate acrylic resin of an orthodontic retainer base plate. Iliana Stoeva ${ }^{10}$ reported a case of a woman who developed an oral erythema and oedema of the tongue, lips, and eyelids, only 10 hours after the placement of new dentures. This proves that if early symptoms are noticed, generalized and associated with difficulties of breathing, allergic reactions is extreme and urgent treatment should be performed. However, positive reactions to dentures and orthodontic appliances are defined by stomatitis marking in general, the appliances contours and are associated with difficulties in swallowing and a bitter taste. ${ }^{12}$ Whereas of acrylic resin fixed crowns, lesions are opposing the interim restoration and marked on the contouring gingiva.

As provisionals are usually cemented with eugenol based temporary types of cement especially for vital teeth, it is necessary to determine whether eugenol is involved or not in the occurring allergic reactions. In fact, Camilla Ahlagrem ${ }^{13}$ reported that eugenol could be a sensitizer provoking an allergy.

These combinations confirm the need identification of the sensitizer, where the patch testing is accepted as a reliable method of detection and diagnosis in contact reactions. ${ }^{14}$ In fact, the clinical symptoms experienced by our patient combined erythema and yellowish-white patches opposing the crown as well as the impression of the provisional graved on the tongue lead to suspicion of allergy indicating this patch testing to identify the allergen. The severe reaction to monomer as well as the weak reaction to polymerized resin both proved that our patient developed a hypersensitivity to the monomer. The use of patch testing shouldn't, however, be routine unless typical characteristics of allergic reactions are detected. ${ }^{15}$

Furthermore, the reliability of patch testing associated with ethical rules proved the paucity of histological findings in the case of allergic manifestations. Unlike other clinical situations, the need for a crown lengthening in our case gave us the opportunity to utilize the fragment of gingiva, after healing, for a histological investigation. The granulation tissue and the polymorphic inflammatory infiltrated associating lymphocytes, plasmocytes, neutrophilic polynuclears and eosinophils were probably explained by the gingiva reaction to the residual monomer leached from the relining resin.

As hypersensitive reactions are mainly determined by contact sites, and like any other treatment in case of allergic manifestations, the recommended treatment for allergic patients to methyl methacrylate is to avoid any dermatological and mucosal contact with this materials. Provisionals should be then performed using aluminum shell crowns for posterior teeth and polycarbonate crowns for anterior teeth. As relining is necessary to correctly fit these interim restorations, protection of the patient's lips and oral mucosa with petroleum jelly is recommended. The relining materials should be a fast setting acrylic resin (Unifast LC acrylic resin) placed for only 30 seconds, then polymerized outside the oral cavity to avoid contact with the patient's oral mucosa. ${ }^{1}$ Otherwise, laboratory made provisionals can provide heat-cured shells or interim restorations which need only a slight relining before temporary seating. It is advised to immerse cured provisionals in water 24 hours before temporary cementation to minimize the risk of irritation of surrounding tissues by the released monomer. ${ }^{16,17}$

\section{CONCLUSION}

Dental materials, mainly acrylic resins, can be health hazarding to patients. Awareness of hypersensitivity that can occur to acrylic resins leads to precise diagnosis and a well-guided treatment decision. 


\section{REFERENCES}

1. Hochman N, Zalkind M. Hypersensitivity to methyl methacrylate: mode of treatment. The Journal of prosthetic dentistry. 1997;77:93-6.

2. Gawkrodger D. Investigation of reactions to dental materials. British Journal of Dermatology. 2005; 153:479-85.

3. Ivković $N$, Božović $D$, Ristić $S$, Mirjanić $V$, Janković $\mathrm{O}$. The residual monomer in dental acrylic resin and its adverse effects. Contemporary Materials. 2013;1:84-91.

4. Bhola R, Bhola SM, Liang $H$, Mishra B. Biocompatible denture polymers-a review. Trends in Biomaterials and Artificial Organ. 2010;23:129-36.

5. Tashkov W, Getchev V. Determination of unpolymerized methyl methacrylate in contact lenses by headspace gas chromatography. Chromatographia. 1993;37:546-8.

6. Davy KW, Braden M. Residual monomer in acrylic polymers. Biomaterials. 1991;12:540-4.

7. Sadamori S, Kotani H, Hamada T. The usage period of dentures and their residual monomer contents. The Journal of prosthetic dentistry. 1992;68:374-6.

8. Bettencourt AF, Neves CB, de Almeida MS, Pinheiro LM, Lopes LP, Castro MF. Biodegradation of acrylic based resins: A review. dental materials. 2010;26:e171-e80.

9. Braun K, N Mello J, N Rached R, Del Bel Cury A. Surface texture and some properties of acrylic resins submitted to chemical polishing. Journal of oral rehabilitation. 2003;30:91-8.

10. Nunes de Mello JA, Olmedo Braun K, Nunes Rached R, Del Bel Cury AA. Reducing the negative effects of chemical polishing in acrylic resins by use of an additional cycle of polymerization. The Journal of prosthetic dentistry. 2003;89:598-602.

11. Fisher AA. Allergic sensitization of the skin and oral mucosa to acrylic resin denture materials. The Journal of prosthetic dentistry. 1956;6: 593-602.

12. Gonçalves TS, Morganti MA, Campos LC, Rizzatto $S$, Menezes LM. Allergy to autopolymerized acrylic resin in an orthodontic patient. American journal of orthodontics and dentofacial orthopedics. 2006;129:431-5.
13. Ahlgren $\mathrm{C}$, Axell $\mathrm{T}$, Moller $\mathrm{H}$, Isaksson $\mathrm{M}$, Liedholm R, Bruze M. Contact allergies to potential allergens in patients with oral lichen lesions. Clinical oral investigations. 2014;18: 227-37.

14. Spiewak R. Patch testing for contact allergy and allergic contact dermatitis. Open Allergy J. 2008;1:42-51.

15. Wiltshire WA, Ferreira MR, Ligthelm AJ. Allergies to dental materials. Quintessence International. 1996;27:513-20.

16. Kedjarune $\mathrm{U}$, Charoenworaluk $\mathrm{N}$, Koontongkaew S. Release of methyl methacrylate from heat-cured and auto polymerized resins: cytotoxicity testing related to the residual monomer. Australian dental journal. 1999;44:25-30.

17. Baker S, Brooks SC, Walker DM. The release of residual monomeric methyl methacrylate from acrylic appliances in the human mouth: an assay for monomer in saliva. Journal of dental research. 1988;67:1295-9. 